Thorax (1954), 9, 211.

\title{
TREATMENT OF PULMONARY TUBERCULOSIS BY THORA- COPLASTY IN PATIENTS OVER 50 YEARS OF AGE \\ BY
}

\author{
PETER BEACONSFIELD, H. S. COULTHARD, AND F. G. KERGIN \\ From the Toronto Hospital for the Treatment of Tuberculosis, and the Department of Surgery, University of Toronto, \\ Ontario, Canada
}

(RECEIVED FOR PUBLICATION OCTOBER 10, 1953)

The lengthening expectation of life has led to a marked increase in the proportion of the population who are over 50 years of age. This is reflected by an increase, which is both actual and proportionate, in the number of patients in the older age group who require treatment for tuberculosis. In the Province of Ontario in 1943, 16.3\% of the 2,850 patients admitted to sanatoria were over 50 years of age and in 1952 the figure had risen to $25.3 \%$ of 3,116 patients. For reasons which are not so obvious $78 \%$ of these are men compared with $52 \%$ of men in the under-50 group.

Provided that the tuberculosis can be brought under control, the over-50 group have a considerable expectation of life and capability of a useful contribution to the economy of the country; there is no justification for withholding from them any of the methods of treatment which have proved useful in a younger age group, provided it is demonstrated that the older patients respond favourably. It is apparent from the literature that in some centres there has been a reluctance to subject older patients to surgical treatment for tuberculosis and it is possible that the more conservative methods of collapse therapy have been pushed beyond their proper indications in dealing with this group. Overhol (1940), Shapiro and Munz (1940), Rudolph (1942), and Zuelka, Adams, and Bloch (1946) have all reported favourably on the response of older patients to treatment by thoracoplasty.

In these days the use of anti-tuberculosis drugs and an increasing application of pulmonary excision to the treatment of tuberculosis have to a certain degree modified the indications for thoracoplasty, but it is probable that the operation will continue to hold a place in therapy. In the treatment of older people perhaps one should be less inclined to undertake a more dangerous excision operation in an attempt to eradicate a focus of disease and more content to accept a state of quiescence with the diseased lung still in situ under a thoracoplasty.

\section{The Present Investigation}

In order to investigate the response of older people to treatment by thoracoplasty a study has been made at the Toronto Hospital for Tuberculosis of all the patients over 50 years of age who have been so treated in the 17-year period from 1933 to 1949 inclusive. There are 55 patients in the group ranging in age from 50 to 68 years at the time of operation. This represents $7.8 \%$ of all the patients treated by thoracoplasty during that period. The subsequent course of all the patients in the group is known. The period of observation varies from a maximum of 21 years to a minimum of four years; as is to be expected there has been a considerable mortality among the earlier members of the group from causes other than tuberculosis.

\section{Age AND SeX}

There were 42 men and 13 women in the group and their ages were as follows: from 50 to 55 years, 44 patients; from 56 to 60 years, nine patients; over 60 years, two patients.

Both the patients in the third group, one a man and the other a woman, were 68 years of age at the time of thoracoplasty and recovered well from the operation, which in each case was performed in two stages. The man died three years later from carcinoma of the caecum and the woman six years later from hypertensive cardiovascular disease.

\section{EXTENT OF DISEASE AND INDICATIONS FOR THORACOPLASTY}

According to the standards established by the National Tuberculosis Association the extent of the disease in this group of patients was classified as follows: (1) far advanced in 24. patients, unilateral in eight, bilateral in 16 (bilateral cavitation five); (2) moderately advanced in 31 patients, unilateral in 24 , bilateral in seven (bilateral cavitation none). 
Tuberculous empyema following artificial pneumothorax complicated the problem in two patients, one of whom survived for 13 years and the other is still living after 16 years. Giant cavitation (over $4 \mathrm{~cm}$.) was present in five patients.

During the period under review thoracoplasty had the same indications in the older age group as in the younger patients. It was undertaken for persistent cavitation which could not be collapsed by other means when the general condition of the patient did not contraindicate a major operation.

\section{Duration of Disease}

As reckoned from the first recognition of positive sputum until operation, the duration of the disease in this group of patients was as follows: over two years in 17 patients $(30 \%)$; from one to two years in 26 patients $(47 \%)$; less than one year in 12 patients $(23 \%)$.

The oldest patient had been under treatment intermittently for 21 years, but $22 \%$ of the patients had never been treated for pulmonary tuberculosis until they had passed the age of 50 years.

\section{Pre-operative Treatment}

In no case was thoracoplasty undertaken in less than six months from the time of admission to a sanatorium and the average pre-operative stay was 11 months. Bronchoscopic examination was a routine pre-operative measure after 1940 . Tuberculous bronchitis was found in 17 of the patients and associated tuberculous laryngitis in two patients. Streptomycin was not available before 1948 but after that date was used for the treatment of tuberculous bronchitis and for a relatively short period before and after operation in the poor-risk patients. Long-term combined chemotherapy had not been introduced at the period under review. A total of 21 patients received streptomycin.

Seven of the patients had been treated by artificial pneumothorax for from six months to six years. In 16 other patients an attempt was made to establish artificial pneumothorax but either the attempt was unsuccessful or the pneumothorax was abandoned at once due to the presence of adhesions not amenable to pneumonolysis. Artificial pneumoperitoneum was instituted in one patient but abandoned within a month. Diaphragmatic paralysis was used in eight patients including two treated by artificial pneumothorax. Cavity drainage before thoracoplasty was used in one case of giant cavity. The remaining 24. patients did not receive any collapse therapy before thoracoplasty, but as artificial pneumothorax could not be obtained or was abandoned immediately in 16 others and pneumoperitoneum was given up after one mont度 in one of the patients, it is correct to say that the thoracoplasty was primary and was preceded onl by rest in 4.1 patients or $75 \%$ of the group.

\section{Associated Conditions}

Sixteen of the patients showed associated condiz tions of some significance, which were as follows myocardial damage, seven patients, diabetes, thre patients, extrapulmonary tuberculosis, three patientso gastric ulcer, two patients, and epilepsy, one patientw

In the group with cardiac disease four patient had a two-stage thoracoplasty of six or seven ribs and two had a three-stage thoracoplasty of eight of nine ribs. Four patients had no post-operative complication, two had moderate dyspnoea, and on patient who had auricular fibrillation develope mesenteric embolism seven days after the first stage thoracoplasty of three ribs and required resection of a portion of the small bowel. No further thoracos plasty was done but he remains well five years latec

Two of the diabetic patients did well but the third, who also had severe heart disease, developeg infection in the wound and lobar atelectasis an died.

Two of the patients with extrapulmonary tubex culosis had renal tuberculosis and the third has Pott's disease. They all recovered well from the thoracoplasty but one of the patients with renal disease died two years later from uraemia.

\section{Surgical Treatment}

Two patients had bilateral thoracoplasties, so 5 thoracoplasty operations were done on 55 patien with a total of 115 stages. Four patients had fou or five ribs removed at a single stage combined with apicolysis. The others had the standara modern type of thoracoplasty with removal of transverse processes below the first. The operation was done in two stages for the six or seven ris thoracoplasties (40 patients) and in three stages fox. the eight to $11 \mathrm{rib}$ thoracoplasties (nine patients The second stage was not undertaken in four patients because of pneumonia in one, progressive tuberculosis in a second, and mesenteric embolisiop in two others.

Except for the earliest cases the anaesthetic used has been cyclopropane administered by endotracheg: tube. For the last 10 years of this series a blood transfusion has been given at each thoracoplast stage.

\section{Post-OPERATIVE Complications}

Four patients died within the first four monthes as a direct result of the operation. One was the 
diabetic patient already mentioned who developed atelectasis of a lobe, infection of the wound, and his diabetes went out of control. Another patient in whom the pleura had been torn developed a pleural effusion and pneumonia and died. Another patient in whom the pleura had been torn developed empyema and a bronchopleural fistula and died. The fourth patient who died was one of the two patients in the series who developed mesenteric embolism.

The other complications which were of some importance but not fatal were as follows: Wound infection, superficial, two patients; torn pleura, effusion only, four patients; pleural effusion without pleural tear, three patients; mesenteric embolism, one patient; cardiac decompensation, three patients; cyclopropane reaction necessitating postponement of operation, two patients; painful catching scapula, five patient .

Two of the patients who had scapular pain were relieved after procaine injections, two following resection of a short segment of rib, and one continued to complain.

\section{RESULTS OF TREATMENT}

In assessing the results of treatment by thoracoplasty the patients may be conveniently divided into four groups.

Group 1.-A good result implies that there is radiological evidence of cavity closure and within a year there is persisting bacterial conversion of the sputum as determined by repeated culture tests.

Group 2.-There is a small group of patients whose radiographs have been stable since the first post-operative year with no evidence of persisting cavitation but who occasionally produce sputum which is positive on culture. Only one such specimen may be found in many years of follow-up examination. Most of these people have been well and working for years but the fact that they can produce sputum containing tubercle bacilli indicates that the infection is still present.

Group 3.-Another group may show great improvement following thoracoplasty but fail to achieve cavity closure or sputum conversion unless this treatment is supplemented by further measures such as a prolonged course of antibiotic therapy or excision of the diseased lobe. They may then remain well and represent a successful outcome from treatment but not from thoracoplasty.

Group 4.-There is a group of frank failures including patients who die as the result of the operation or from progressive pulmonary tuberculosis.
The 55 patients under discussion may be classified as follows:

(1) Radiographs stable and sputum always negative after thoracoplasty:
Living .
Dead (coronary occlusion $\ddot{2}$, carcinoma 1 , pneumonia 1)
Total

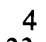
$33(60 \%)$

(2) Radiographs stable but sputum positive for tubercle bacilli :

On one occasion (5 to 11 years after operation) .. ..

On several occasions (2 to ii years after operation) (3 have died, coronary occlusion 1 , carcinoma 1 , hypertension 1) . . . . ..

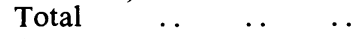

(3) Supplementary treatment required for 2 to 4 years but now sputum negative and patient well (lobestomy 1, pneumoperitoneum 1, chemotherapy 1)

(4) Death while tuberculosis active:

Due to post-operative com-

plications .. $\quad . . \quad \ldots .44$

Due to progressive tuber$\begin{array}{llll}\text { culosis } & \ldots & \ldots & \ldots\end{array}$

$\begin{array}{lllll}\text { Total } & \ldots & \ldots & \ldots & 9(16.5 \%)\end{array}$

\section{$3(5 \cdot 5 \%)$}

5

At the end of 1953,16 of the 55 patients were dead, a mortality rate of $29 \%$ during a period of observation from four to 21 years. Of these deaths four were due to post-operative complications which have already been described, five were due to progressive tuberculosis, and seven to unrelated conditions.

The five patients who died of progressive tuberculosis represent $9 \%$ of the group. All had bilateral, far-advanced tuberculosis. Two patients died without leaving the sanatorium two and a half and three years after operation. One of them also had renal tuberculosis. One patient was said to have died of influenza three years after operation but as no necropsy was performed he is considered to have died of tuberculosis. One patient lived as an invalid for four and a half years after thoracoplasty for a giant cavity and then died suddenly from a massive pulmonary haemorrhage. The fifth patient developed a large cavity in the opposite lung but his respiratory reserve was too low to permit collapse therapy. In spite of chemotherapy the disease progressed and he died nine years after thoracoplasty.

Of seven patients who died from non-tuberculous disease, four died from cardiovascular disease, two from carcinoma, and one from pneumonia.

\section{Sputum Conversion}

Before 1940, sputum culture at the Toronto Hospital for Tuberculosis was done occasionally, 
but not routinely, and examination of specimens was done less frequently for each patient than was the case after 1940. Most of the sputum tests made on the seven thoracoplasty cases whose operations were done between 1933 and 1939 were concentrations, but thereafter it became routine to culture the sputum or fasting gastric contents of all cases having negative concentrations and of those having no sputum at all. Ultimately it became the accepted practice to culture all specimens, even when the concentration was positive.

Following discharge from hospital, most patients have been examined periodically at the Gage Institute in Toronto, but some have been checked at other sanatoria or other chest clinics. When there is sputum, it is examined by culture, but if there is no sputum no attempt is made to obtain a specimen by gastric lavage. In Table I the sputum

TABI.E I

RESULTS OF SPUTUM CONVERSION

\begin{tabular}{|c|c|c|c|c|c|}
\hline \multirow[b]{2}{*}{$\begin{array}{c}\text { Sputum } \\
\text { in Sanatorium }\end{array}$} & \multirow[b]{2}{*}{ Total } & \multicolumn{4}{|c|}{ Sputum after Discharge from Sanatorium } \\
\hline & & $\begin{array}{c}\text { Persis- } \\
\text { tently } \\
\text { Negative }\end{array}$ & $\begin{array}{c}\text { Positive } \\
\text { Only } \\
\text { Once }\end{array}$ & $\begin{array}{c}\text { Positive } \\
\text { Inter- } \\
\text { mittently }\end{array}$ & $\begin{array}{c}\text { Positive } \\
\text { at } \\
\text { Death }\end{array}$ \\
\hline $\begin{array}{l}\text { Converted } 1-12 \\
\text { months pre-op- } \\
\text { eratively }\end{array}$ & 21 & $17(80 \%)$ & $2(10 \%)$ & $1(5 \%)$ & $1(5 \%)$ \\
\hline $\begin{array}{c}\text { Converted } 1-12 \\
\text { months post-op- } \\
\text { eratively }\end{array}$ & 19 & $16(84 \%)$ & $2(11 \%)$ & $1(5 \%)$ & - \\
\hline $\begin{array}{l}\text { Converted } 1 \frac{1}{2} \text { to } 5 \\
\text { years post-op- } \\
\text { eratively }\end{array}$ & 6 & $3(50 \%)$ & 一 & $3(50 \%)$ & - \\
\hline $\begin{array}{l}\text { Not converted .. } \\
\text { Post-operative } \\
\text { deaths }\end{array}$ & $\begin{array}{l}5 \\
4\end{array}$ & 二 & 二 & $1(20 \%)$ & $\begin{array}{l}4(80 \%) \\
4(100 \%)\end{array}$ \\
\hline Total & 55 & $36(66 \%)$ & $4(7 \%)$ & $6(11 \%)$ & $9(16 \%)$ \\
\hline
\end{tabular}

behaviour of each case while in the sanatorium is compared with sputum findings after discharge, it being understood that since 1940 all tests have been verified by culture. In the first group $s$ : utum conversion occurred before thoracoplasty, so the operation was done to obtain cavity closure. However, the results in this group are no better than those in the second group, converted after thoracoplasty, provided conversion took place within one year of operation. In the third group are those whose sputum remained positive from one and a half to five years after operation, and half of these tended to show positive sputum from time to time after discharge. In the fourth group sputum was not converted and only one of these patients is alive and well and has a stable radiograph.

With regard to sputum conversion the end-result of treatment may be considered fairly satisfactory. If the six patients who have shown intermittently positive sputum are considered poor results there are still 40 patients, or $73 \%$ of the total, who have never relapsed radiologically although four of them have relapsed bacteriologically on one occasion each over many years of observation.

\section{ECONOMIC END-RESULTS}

One might expect that the majority of tuberculosis patients in this age group would remaino invalids or at least fail to return to an active occu- $-\vec{f}$ pation. They have had a prolonged period of morbidity culminating in a major operation whichio inevitably has produced some loss of respiratoryis function. In fact the greater proportion have been rehabilitated. Nineteen men have been able to 9 return to work similar to that done before entering sanatorium, and nine women returned to house- $\Phi$ keeping. In addition six men were able to change $\underset{\mathbb{\Phi}}{\vec{T}}$ to a lighter occupation such as elevator operator, 3 hospital orderly, or night watchman. Thus 34 石 $(67 \%)$ of the 51 patients who survived the operation have been able to do useful work since leaving the sanatorium. Of the remaining 17 patients, five ${ }^{-}$ suffered from progressive tuberculosis and died four are retired and do not have to work, two haves died of coronary occlusion, and one from carcinoma of the caecum. Four are unable to work as the result of the pulmonary disease and its treatment, $\mathbb{\mathscr { Q }}$ and one is in a sanatorium because of intermittently $\overrightarrow{\vec{O}}$ positive sputum.

\section{Discussion}

In assessing the results of treatment in this group of patients it must be remembered that the period응 under review begins in 1933, which is long beforex the days of antibiotics and even before the advent of chemotherapy. Of the 55 patients, only 21. received streptomycin and none were prepared foro operation by the modern long-term regimen of a combination of anti-tuberculosis drugs. In Table II윽 the mortality rate for patients over 50 years of age $>$ is compared with the rate in the under-50 group, all deaths within four months of operation being considered as operative mortality. It is to be noted that the figures in the table refer to patients and noto

TABLE II

THORACOPLASTY OPERATIONS 1933 TO 1949

\begin{tabular}{|c|c|c|c|c|}
\hline \multirow{2}{*}{$\begin{array}{c}\text { Year of } \\
\text { Operation }\end{array}$} & \multicolumn{2}{|c|}{ Over 50 Years of Age } & \multicolumn{2}{|c|}{ Under 50 Years of Age } \\
\hline & $\begin{array}{l}\text { No. of } \\
\text { Patients }\end{array}$ & Mortality & $\begin{array}{l}\text { No. of } \\
\text { Patients }\end{array}$ & Mortality \\
\hline $\begin{array}{l}1933-9 \\
1940-4 \\
1945-9\end{array}$ & $\begin{array}{r}7 \\
21 \\
27\end{array}$ & $\begin{array}{l}0 \\
3(14 \%) \\
1(37 \%)\end{array}$ & $\begin{array}{l}192 \\
207 \\
257\end{array}$ & $\begin{array}{r}10(5.2 \%) \\
6(2.9 \%) \\
3(1.2 \%) \\
\end{array}$ \\
\hline Total & 55 & $4(7 \cdot 3 \%)$ & 656 & $19(2 \cdot 6 \%)$ \\
\hline
\end{tabular}


to stages. There was an average of two thoracoplasty stages per patient.

These figures indicate that during all the period covered by the study the older patients have faced about three times as great a risk from operation as the younger group. However, in the most recent five-year period the mortality rate for the senior group has declined to $3.7 \%$, which is not prohibitive.

Two of the deaths in the older group were from complications due to a technical error. These patients do not tolerate complications as well as the younger patients, and the operations should be done with special care by the more experienced members of the operating team.

There is more morbidity following operation in older patients. There is more pain related to the chest wall and spine and it lasts longer. Unless supervision is close and physiotherapy adequate, they are likely to develop a stiff shoulder on the side of operation. In most patients recovery from the mechanical disturbance of the operation was slower than in the younger patients but no less complete.

During the period under review detailed studies of respiratory function were not done. The ability of a patient to tolerate collapse therapy was assessed by observations of his reactions to exercise, fuoroscopic observations of the chest wall and diaphragmatic movements, and measurements of vital capacity. The measured loss of vital capacity following thoracoplasty varied from $300 \mathrm{ml}$. to $1,200 \mathrm{ml}$. and was by no means predictable nor proportional to the extent of the thoracoplasty. Only two of the patients suffered from a marked restriction of exercise tolerance after operation. That the majority of the others had a useful range of respiratory function is indicated by the relatively large proportion who were re-employed.

As far as control of pulmonary tuberculosis is concerned, the results obtained are reasonably satisfactory. Forty patients, or $73 \%$ of the group, have carried on with no symptoms of tuberculosis and no radiographic evidence of relapse. Over a very long period of observation four of this number have shown a positive culture of sputum on one occasion only. It is to be expected that in the future better results will be obtained by using thoracoplasty after prolonged treatment by antituberculosis drugs and also by employing excisional surgery for those patients with disease of doubtful suitability for collapse by thoracoplasty. It can be concluded that patients between 50 and 70 years of age respond to thoracoplasty treatment in the same way as patients under 50 years of age and that the operation should be used for the same indications in the two age groups.

Seven of these patients were treated by artificial pneumothorax for a period of from six months to six years, and two of them developed tuberculous empyema. These patients would have been served better by a primary thoracoplasty than they were by persisting with an ineffective artificial pneumothorax. In the case of the two patients who developed empyema the thoracoplasty might have been much less extensive if done as a primary procedure.

\section{SumMaRY}

During the period from 1933 to 1949 inclusive 55 patients who were over 50 years of age were treated by thoracoplasty for pulmonary tuberculosis at the Toronto Hospital for Tuberculosis. There has been a complete follow-up of the group until the end of 1953.

Four of the patients died as the result of the operation, five have died since of tuberculosis, and seven have died of other causes. Forty, or $73 \%$ of the group, achieved satisfactory control of disease following the operation.

When the result of treatment in the older patients is compared with that in younger patients it is apparent that the senior group face a greater risk from the operation and that they are subject to more post-operative morbidity, but the response of the disease to treatment by thoracoplasty is similar in the two age groups.

\section{REFERENCES}

Overholt, R. H. (1940). Amer. Rev. Tuberc., 41, 143.

Rudolph, C. W. (1942). Med. Bull. Veterans Adm., 19, 1

Shapiro, R., and Munz, W. (1940). Amer. Rev. Tuberc., 42, 631.

Zuelka, S. E., Adams, W. E., and Bloch, R. C. (1946). Ibid., 54, 368. 